Tropical Journal of Pharmaceutical Research December 2015; 14 (12): 2293-2297

ISSN: 1596-5996 (print); 1596-9827 (electronic)

(1) Pharmacotherapy Group, Faculty of Pharmacy, University of Benin, Benin City, 300001 Nigeria.

All rights reserved.

Available online at http://www.tjpr.org

Original Research Article

http://dx.doi.org/10.4314/tjpr.v14i12.20

\title{
The Approach of Pharmacy Students Towards Communication of Medication Errors in Karachi, Pakistan
}

\author{
Wajiha Iffat ${ }^{1 *}$, Riffat Yasmin ${ }^{1}$, Sadia Shakeel ${ }^{1}$, Fariya Zafar $^{2}$, Shehla Imam ${ }^{3}$, \\ Abida Sultana ${ }^{4}$, Tehseen Quds ${ }^{1}$ and Yumna Nida Yousuf ${ }^{1}$ \\ ${ }^{1}$ Dow College of Pharmacy, Dow University of Health Sciences, ${ }^{2}$ Faculty of Pharmacy, Zia uddin Medical University, ${ }^{3}$ Faculty of \\ Pharmacy, Jinnah University for Women, ${ }^{4}$ Department of Pharmaceutics, Faculty of Pharmacy, University of Karachi, Karachi, \\ Pakistan
}

${ }^{*}$ For correspondence: Email: wajiha.iffat@duhs.edu.pk; Tel: +923343422348

Received: 27 December 2014

Revised accepted: 2 October 2015

\begin{abstract}
Purpose: To assess pharmacy students' knowledge of communicating medication errors in Karachi, Pakistan.

Methods: The study design was cross-sectional and conducted from February to May 2014. A previously validated questionnaire was adopted, modified and distributed to final year pharmacy students in four universities of Karachi. Descriptive statistics were used to present students' demographic information and their response to the questionnaire items. Pearson chi square test and Logistic regression model were executed to evaluate the association of gender and institution of students with their response.

Results: Out of 600 survey questionnaires distributed, only 464 were returned in useable form, giving a response rate of $77.33 \%$. A majority of the students showed moderately positive attitude towards general communication and training in communicating medication errors. More than $40 \%$ of the respondents were not satisfied with the training they received in communicating and reporting incidence of medication errors. Incorrect drug (14.65\%), incorrect dose (8.40\%) and improper storage of medicines $(7.97 \%)$ were the most common errors observed by the students during clerkship.

Conclusion: The findings indicate the need for a more standardized approach to improving knowledge of medication errors as well as training in the communication of occurrence of medication errors.
\end{abstract}

Keywords: Communication, Medication error, Pharmacy students, Standardized training

Tropical Journal of Pharmaceutical Research is indexed by Science Citation Index (SciSearch), Scopus, International Pharmaceutical Abstract, Chemical Abstracts, Embase, Index Copernicus, EBSCO, African Index Medicus, JournalSeek, Journal Citation Reports/Science Edition, Directory of Open Access Journals (DOAJ), African Journal Online, Bioline International, Open-J-Gate and Pharmacy Abstracts

\section{INTRODUCTION}

An error occurring in drug prescribing, dispensing, administration, or monitoring is known as medication error [1]. These errors range from minor discomfort to substantial morbidity that may prolong hospitalization or even lead to death among hospitalized and ambulatory patients [2]. Sources of medication errors include: excess work load, lack of professional competency, inappropriate training, rush at pharmacy, inadequate availability of patient information, poor communication, self administration of drugs by ambulatory patients etc [3]. A medication error is categorized as commission or omission error, depending upon taking incorrect action against an error [4].

Mostly the errors occur during prescribing, followed by drug administration, dispensing and transcription. In prescription writing, the errors occurred owing to the illegible handwriting, 
ambiguous and incomplete orders. Interventions in prescriptions by pharmacists can minimize the harms associated with poor prescribing of medicines.

Wilson and Sullivan stated that pharmacist is of great help to ensure medication safety by preventing the risk associated with medications error [5]. For this purpose, FDA planned to improve pharmacists' understanding about their participation in ensuring patient's safety from using different medicines [6]. Several studies have conducted on this issue $[7,8]$.

This study was designed to evaluate the understanding of undergraduate pharmacy students regarding the communication of medication errors, as no such study has been conducted recently in Karachi, Pakistan. In other parts of the world, few studies have been conducted on the issue $[9,10]$.

\section{EXPERIMENTAL}

\section{Study design and setting}

This transversal study was conducted from February to May 2014 by adopting a prevalidated questionnaire distributed to senior pharmacy final-year pharmacy students of different private and public sector universities in Karachi. Around 150 questionnaires were distributed in each university. The sample size was calculated by Open $\mathrm{Epi}{ }^{\circledR}$ online software and non-probability sampling technique was adopted. Items rated on a Likert scale ranging from $1=$ strongly disagree to $5=$ strongly agree .

There was no earlier estimation regarding the knowledge of communication of medication errors in Pakistan. Therefore, it was assumed that the prevalence of knowledge was $50 \%$ and calculated the required sample for our survey with an allowable error of $5 \%$ and $95 \%$ confidence limits. Overall, four hundred and sixty four students participated in the study. Students were encouraged to fill up the given questionnaire on spot. After completion, the questionnaires were subsequently collected for further analysis.

\section{Ethical approval}

Prior verbal ethical approval was obtained from each institution's head of department to instigate the study in their institute. Each institution's head of department and the students' participating in the study were briefed about the rationale of the study. Participants were assured about the confidentiality of their personal information and responses.

\section{Data collection}

A pre-validated questionnaire used in other studies was adapted and modified [11]. It consisted of 15 items exploring the background, communication attitudes, training in communication about medication errors, ethical and practical measures regarding medication errors and types of errors commonly observed during the clerkship.

\section{Statistical analysis}

The completed questionnaires were analyzed using Statistical Package for Social Sciences (SPSS 20.0, Chicago, IL). Descriptive statistics was used to analyze students' demographic information and their response to the questionnaire items.

Pearson chi square test and logistic regression model were executed to evaluate the association of gender and institution of students with their response to the questionnaire, and $p<0.05$ was set as the level of significance.

\section{RESULTS}

\section{Demographic characteristics}

Out of 600 survey questionnaires, 511 were returned back and only 464 were in useable form. Hence the response rate was $77.33 \%$. Table 1 showed the demographic of the study population. The study population comprised of $85.56 \%$ females. Near about $55.6 \%$ of the participants belonged to the public sector and $44.4 \%$ belonged to private sector universities.

Responses of the students regarding factors providing convenience in dealing with medication errors showed that $80.6 \%$ of the students feel more comfortable in dealing with patients of same gender. More than $85 \%$ students feel more convenient in dealing with literate patients and $75 \%$ students select hospital as an area of ideal pharmacy practice site.

Table 1: Demographic profile of students

\begin{tabular}{lc}
\hline Variable & $\mathbf{N}(\%)$ \\
\hline Gender & \\
Male & $67(14.43)$ \\
Female & $397(85.56)$ \\
Institute & \\
Public sector & $258(55.60)$ \\
Private sector & $206(44.4)$ \\
\hline
\end{tabular}

Trop J Pharm Res, December 2015; 14(12): 2294 


\section{Students' knowledge regarding the communication of medication errors}

Responses of students regarding general communication attitudes and training about medication errors are recorded in Table 2 . Majority of the students showed moderately positive attitude towards general communication attitude and training in communicating medication errors. More than $40 \%$ of the respondents were not contented with the training they received on how to communicate the patients about the incidence of a medication error and how to report a medication error. Students felt more comfortable in reporting such errors to peer as compared to supervisor.

Influence of gender and institutes on students' opinions was studied using Pearson chi square test, a non-parametric test. The influence of gender had a significant impact on their responses i.e. they know what to tell patients when a medication error occurs $(p=0.016)$ and how to report a medication error $(p=0.002)$. Compared to gender, institutes of respondents have shown more significant influence on majority opinions i.e. they received sufficient training on communication issues that contribute to medication errors $(p<0.0001)$, they received sufficient training on how to communicate with patients about the occurrence of a medication error $(p=0.003)$ and they received sufficient training on how to communicate with other healthcare professional about the occurrence of a medication error $(p=0.044)$.

Logistic regression model was used to evaluate the association of gender and institute of students with their response. Male students more likely to consider the extent of their knowledge provide convenience in dealing with medication errors; while students of private institutes are more likely to consider the affect of adequate training received on communicating medication errors provide convenience in dealing with medication errors.

\section{Ethical and practical measures}

A majority of the students (34.69\%) considered honesty and empathy with patient as an ethical measure that should be adopted when dealing with patients who have been victim of medication error.

Table 2: Students' perceptions of training and knowledge regarding the communication of medication errors

\begin{tabular}{|c|c|c|c|c|c|c|}
\hline Statement & $\begin{array}{c}\text { Strongly } \\
\text { agree }\end{array}$ & Agree & eutral & Dis & $\begin{array}{l}\text { Strongly } \\
\text { disagree }\end{array}$ & Mean \\
\hline d sufficient training on comm & 9) & & & & & 99 \\
\hline to communicate & 7) & & 7) & )) & 6) & $2.69 \pm 1.05$ \\
\hline $\begin{array}{l}\text { I received sufficient training on how to communicate } \\
\text { with other healthcare professional about the } \\
\text { occurrence of a medication error. }\end{array}$ & 74) & 10 & 9) & 6) & 1) & 01 \\
\hline when a medication error & & & & & & \\
\hline & $7(7.97)$ & 216 & $148(31.89)$ & $55(1$ & $8(1.72)$ & $3.47 \pm 0.86$ \\
\hline ortable reporting to a fellow $\mathrm{c}$ & $2(9.05)$ & $197(42.45)$ & $158(34.05)$ & Soll & $12(2.58)$ & $3.43 \pm 0.90$ \\
\hline $\begin{array}{l}\text { I felt comfortable reporting to a su } \\
\text { intercepted or actual medication e } \\
\text { else made in the pharmacy. }\end{array}$ & (9.05) & 179 & 3.18) & 72 & $17(3.66)$ & $3.33 \pm 0.96$ \\
\hline $\begin{array}{l}\text { I observed at least } 1 \text { hospital pharmacy where } \\
\text { everyone knows when an error has been caused, } \\
\text { why it happened, and how to avoid it from happening } \\
\text { again. }\end{array}$ & (9.69) & 161 & 50) & 105 & $30(6.46)$ & \pm 1.08 \\
\hline $\begin{array}{l}\text { I obs } \\
\text { medi } \\
\text { docu }\end{array}$ & $\begin{array}{c}51 \\
10.99)\end{array}$ & $27(27.37)$ & 21) & 132 & $37(7.97)$ & $3.04 \pm 1.14$ \\
\hline $\begin{array}{l}\text { I observed at least } 1 \text { hospital pharm } \\
\text { routinely develops procedures to pr } \\
\text { occurring again }\end{array}$ & $(8.83)$ & $1(30.38)$ & $129(27.80)$ & $16(25)$ & $7(7.97)$ & 1.10 \\
\hline
\end{tabular}


Reassuring the patient that steps will be taken to reduce errors (16.16\%), remain calm and be patient (14\%) and ensuring awareness of situation to all including the patient (12.28\%) were also considerable measures.

Table 3: Practical measures adopted with patients who have been victim of medication error

\begin{tabular}{lc}
\hline Practical measure & $\%$ \\
\hline Collect and verify information & 17.24 \\
Check and verify medication order & 10.34 \\
Error documentation & 4.09 \\
Reporting the error & 4.74 \\
All of them & 63.36 \\
\hline
\end{tabular}

Responses of the students regarding practical measures are recorded in Table 3 . Near about $63 \%$ considered that they will collect and verify all information, check and verify the medication order, error documentation and reporting the error to supervisor as practical measures that should be adopted when dealing with patients who have been victim of medication error.

\section{Awareness of type of error}

Awareness of students about the types of errors commonly observed in a hospital setting is recorded in Table 4 . More than $45 \%$ of the students were aware of different types of medication errors frequently occurring in the hospital.

Table 4: Types of errors commonly observed by pharmacy students

\begin{tabular}{lc}
\hline Error type & $\%$ \\
\hline Incorrect drug & 14.65 \\
Wrong patient & 7.11 \\
Incorrect dose & 8.40 \\
Mislabeling & 4.52 \\
Improperly prepared IV & 2.80 \\
medication & 3.66 \\
Incorrect quantity & 7.97 \\
Improper storage & 4.09 \\
Mishandling of controlled & 46.76 \\
drugs & \\
All of them & \\
\hline
\end{tabular}

\section{DISCUSSION}

This explanatory study was conducted with the primary objective to assess pharmacy students' knowledge of communicating medication errors. As it would provide an understanding how future pharmacists learn the role that communication plays in the occurrence of, reporting, and responding to medication errors. The results of the survey indicate more than $40 \%$ of the respondents were not contented with the training they received on communicating with patients about the incidence of a medication error and to report a medication error. These parallel observations were also reported by Noland and Rickles that majority of respondents received inadequate or no formal useful training on how to deal with the issues relevant to the communication of medication errors [11,12]. However, research has shown that pharmacists who receive more education and training on reporting misadventures are more likely to report them [13]. Student comfort levels vary mainly upon who made the error and to whom the error would be reported. Respondents articulated being most comfy reporting an error to a peer as compared to supervisor.

Majority of the students (34.69\%) considered honesty and empathy with patient as an ethical measure that should be adopted when dealing with patients who have been victim of medication error. The ability of healthcare provider to accurately identify, disclose the error with honesty and transparency and report medication error ensure patient safety. Healthcare professional can minimize medication errors through support and learning from others to cooperate with the organization in preventing recurring errors [14]. Majority of the respondents participating in this study were aware of different types of medication errors. However, it was found that incorrect drug (14.65\%), incorrect dose $(8.40 \%)$ and storage $(7.97 \%)$ were the most common error observed by the pharmacy students during clerkship. Similar findings have been revealed by Demehin et al identifying wrong drug and wrong dose errors in the teaching hospital [15].

Logistic regression model was used to evaluate the association of gender and institute of students with their response. Male students more likely to consider the extent of their knowledge provide convenience in dealing with medication errors; while students of private institutes are more likely to consider the affect of adequate training received on communicating medication errors provide convenience in dealing with medication errors.

Pharmacists being the drug expert are more likely to detect drug misadventures as compared to other healthcare professionals. Their role has been proven to improve many outcomes regarding patient health, including greater patient safety, improved disease and therapy management, identification and prevention of adverse drug events and improved quality of life [10]. Research has shown that pharmacists working in an inpatient pediatric setting could 
have prevented 94 percent of probable drug misadventures [1]. Future pharmacists should be more prepared to recognize the clinical responsibilities by increasing emphasis on clinical education [9].

Pharmacy students should be effectively trained and ensure preeminent practices to generate a learning culture around the incidence and prevention of medication errors. Future research should explore other organizational factors in order to focus on effective ways to respond to and prevent medication errors in the interest of patient care.

\section{Limitations of the study}

This study encountered some limitations. The study did not include practicing pharmacists who would have presented an actual scenario of communication of medication errors. Furthermore, participants in this study were all pharmacy students drawn from different institutes of Karachi and therefore cannot be generalized to the whole of Pakistan.

\section{CONCLUSION}

The findings indicate the need to adopt a more standardized approach to improve the knowledge of medication errors among pharmacy students as well as training in communicating the occurrence of medication error.

\section{REFERENCES}

1. Kaushal R, Bates DW, Landrigan C, McKenna KJ, Clapp $M D$, Federico F. Medication errors and adverse drug events in pediatric inpatients. JAMA. 2001; 285(16): 211-220.

2. Barber N, Rawlins M, Franklin BD. Reducing prescribing error: competence, control, and culture. Qual Saf Health Care. 2003; 12(suppl 1): i29-i32.

3. Cohen MR. Medication errors: Am Pharm Assoc; 2007.

4. Thomsen LA, Winterstein AG, Søndergaard B, Haugbølle LS, Melander A. Systematic review of the incidence and characteristics of preventable adverse drug events in ambulatory care. Ann Pharmacother. 2007; 41(9): 1411-1426.

5. Wilson K, Sullivan M. Preventing medication errors with smart infusion technology. Am J Health Syst Pharm. 2004; 61(2): 177-183.

6. Plan FSA. Charting Our Course for the Future. Washington, DC: Department of Health and Human Services, US Food and Drug Administration; 2007. 2011.

7. Bates DW, Leape LL, Cullen DJ, Laird N, Petersen LA, Teich JM. Effect of computerized physician order entry and a team intervention on prevention of serious medication errors. JAMA. 1998; 280(15): 1311-1316.

8. Iffat W, Shakeel S, Rahim N, Anjum F, Neesar S, Ghayas S. Pakistani physicians knowledge and attitude towards reporting adverse drug reactions. Afr $J$ Pharm Pharacol. 2014; 8(14): 379-385.

9. Johnson MS, Latif DA, Gordon B. Medication error instruction in schools of pharmacy curricula: a descriptive study. Am J Pharm Educ. 2002; 66(4): 364-371.

10. Sukkari SR, Sasich $L D$, Tuttle DA, Abu-Baker AM, Howell $H$. Development and evaluation of a required patient safety course. Am J Pharm Educ. 2008; 72(3): Article 65.

11. Rickles NM, Noland CM, Tramontozzi A, Vinci MA. Pharmacy student knowledge and communication of medication errors. Am J Pharm Educ. 2010; 74(4): Article 60

12. Noland CM, Rickles NM. Reflection and Analysis of How Pharmacy Students Learn to Communicate About Medication Errors. Health commun. 2009; 24(4): 351 360.

13. Su C, Ji H, Su Y. Hospital pharmacists' knowledge and opinions regarding adverse drug reaction reporting in Northern China. Pharmacoepidemiol Drug Saf. 2010; 19(3): 217-222.

14. Denham CR. Trust: The 5 rights of the second victim. $J$ Patient Saf. 2007; 3(2): 107-119.

15. Demehin Al, Babalola OO, Erhun WO. Pharmacists and Nurses perception of medication errors in a Nigerian University Teaching Hospital. Int J Health Res. 2008; 1(2): 51-61. 